\title{
Role of the external drivers in the occurrence of low-latitude ionospheric scintillation revealed by multi-scale analysis
}

\author{
Luca Spogli $^{1,5}{ }^{*}$, Mirko Piersanti ${ }^{2,6}$, Claudio Cesaroni ${ }^{1}$, Massimo Materassi ${ }^{3}$, Antonio Cicone ${ }^{4,10,11}$, \\ Lucilla Alfonsi $^{1}$, Vincenzo Romano ${ }^{1,5}$, and Rodolfo Gerardo Ezquer ${ }^{7,8,9}$ \\ ${ }^{1}$ Istituto Nazionale di Geofisica e Vulcanologia, Rome 00143, Italy \\ 2 National Institute for Nuclear Physics, University of Tor Vergata, Rome 00133, Italy \\ ${ }^{3}$ National Research Council, Institute for Complex Systems ISC-CNR, 50019, Italy \\ ${ }_{5}^{4}$ Department of Information Engineering, Computer Science and Mathematics, University of L'Aquila, 67100 L'Aquila, Italy \\ ${ }^{5}$ SpacEarth Technology, Rome 00143, Italy \\ ${ }^{6}$ Consorzio Area di Ricerca in Astrogeofisica, 67010 L'Aquila, Italy \\ ${ }^{7}$ Laboratorio de Ionósfera, Departemento de Física, FACET, Universidad Nacional de Tucumán, 4000 Tucumán, Argentina \\ ${ }^{8}$ CIASUR, Facultad Regional Tucumán, Universidad Tecnológica Nacional, 4000 Tucumán, Argentina \\ ${ }^{9}$ Consejo Nacional de Investigaciones Científícas y Técnicas, C1033AAJ Buenos Aires, Argentina \\ ${ }^{10}$ Istituto Nazionale di Alta Matematica, 00185 Rome, Italy \\ ${ }^{11}$ Gran Sasso Science Institute, 67100 L'Aquila, Italy
}

Received 19 July 2018 / Accepted 26 August 2019

\begin{abstract}
We analyze the amplitude scintillation on L-band signals over San Miguel de Tucumán (Argentina), focusing on the multi-scale variability and speculating on the possible relationship between forcing factors from the geospace and the ionospheric response. The site is nominally located below the expected position of the southern crest of the Equatorial Ionospheric Anomaly (EIA). For this scope, we concentrate on the period 1-31 March 2011, during which one minor and one moderate storm characterize the first half of the month, while generally quiet conditions of the geospace stand for the second half.

By leveraging on the Adaptive Local Iterative Filtering (ALIF) signal decomposition technique, we investigate the multi-scale properties of Global Navigation Satellite Systems (GNSS) amplitude scintillation and helio-geophysical parameters, looking for possible cause-effect mechanisms relating the former to the latter. Namely, we identify resonant modes in the Akasofu $(\varepsilon)$ parameter as likely related to the frequency components in the time evolution found for the amplitude scintillation index, hence modulating the scintillation itself.
\end{abstract}

Keywords: aeronomy / ionosphere (equatorial) / space weather / irregularities / positioning system

\section{Introduction}

At low latitudes, the morphology of the magnetic field and the electrodynamics of the Earth's ionosphere may allow the formation of post-sunset Equatorial Plasma Bubbles (EPBs). EPBs are known as the principal responsible for the ionospheric scintillation of Global Navigation Satellite Systems (GNSS) signals (see, e.g., Yeh \& Liu 1982; Kintner et al., 2009). In fact, plasma density irregularities embedded in post-sunset EPBs present a wide spectrum of spatial scales that include also those below the Fresnel's scale for L-band signals, being of the order of hundreds of meters. Such a scale identifies the effective sizes to produce amplitude scintillation due to diffraction effects (Wernik \& Liu, 1974; Wernik et al., 2003). Occurrence of

\footnotetext{
*Corresponding author: luca. spogli@ingv. it
}

small-scale irregularities due to post-sunset EPBs maximizes in correspondence with the expected position of the crests of the Equatorial Ionospheric Anomaly (EIA) and their formation is due to the interplay between electrodynamics ( $E \times B$ drift) and gravitational forces (Rishbeth, 1971; Jin et al., 2008; Kelley, 2009; Fejer, 2011; Balan et al., 2018).

Solar events disturb the regular behavior of the magnetosphere-ionosphere system, leading to meaningful changes in the occurrence of ionospheric irregularities producing scintillations. The local day-to-day variability of the irregularities formation and the cause-effect mechanisms linking geospace drivers and found patterns on L-band scintillation are still challenging for the community.

In particular, solar transients affect the magnetosphereionosphere system, possibly leading to a meaningful variation of the electrodynamics of the low latitude ionosphere. Indeed, 
changes in the Equatorial Electrojet (EEJ) due to the external forcing modify the $E \times B$ and then the uplift of the F-layer at the post sunset hours, the position of the crests of the EIA and the occurrence of small-scale irregularities embedded in the post-sunset EPBs.

Such modifications have a dependence on the local time of the storm development (Aarons, 1991) and can either results into an intensification ("super-fountain effect") or a suppression of the irregularities formation. Both effects have been intensively studied in recent and past storms (see, e.g., Tsurutani et al., 2004, 2008; Abdu, 2005; Mannucci et al., 2005; Abdu et al., 2009; Balan et al., 2010; Muella et al., 2010; Zong et al., 2010; Alfonsi et al., 2011, 2013; Astafyeva et al., 2016; Spogli et al., 2016; Tulasi Ram et al., 2016; Olwendo et al., 2017; Piersanti et al., 2017; Venkatesh et al., 2017).

The Prompt Penetration Electric Fields (PPEFs) and the Disturbance Dynamo Electric Fields (DDEFs) are the two main processes responsible for the intensification/suppression of the small-scale irregularities formation. Both are due to the dynamical coupling between solar wind, magnetosphere and ionosphere and are originated in the high-latitude ionospheric sector. In specific, PPEFs are electric fields originating in the outer magnetosphere or in the solar wind that propagate across the Earth's magnetic field line. PPEFs were discovered by Nishida (1968) and their dynamics is triggered by the under/ over-shielding conditions due to the relative intensities of the Region 1 (R1) and Region 2 (R2) field-aligned currents (FACs). Their imbalance following the different phases of a geoeffective solar storm theoretically explains the PPEF (Abdu et al., 2009; Wei et al., 2015; Fejer et al., 2017).

DDEFs are due to the variations in the circulation of the neutral winds induced by auroral heating processes, mainly Joule heating, during storms. The heating in the high-latitude region results into cross-equatorial winds that disturb the neutral thermospheric circulation ruling the equatorial electrodynamics. DDEFs have a delay of 1-3 $\mathrm{h}$ with respect to PPEFs in affecting the low latitude ionosphere (e.g., Scherliess \& Fejer, 1997).

Notwithstanding the current understanding about PPEF and DDEF mechanisms, a complete picture of how cause-effect chain develops from the interplanetary drivers to the ionospheric response recorded at ground is still challenging for the community.

In this work, we study the scintillation patterns on GNSS signals recorded in San Miguel de Tucumán $\left(26.9^{\circ} \mathrm{S}\right.$, $65.4^{\circ} \mathrm{W}$, Argentina), a site located under the southern crest of the EIA (magnetic latitude $15.5^{\circ} \mathrm{S}$ ). The chosen period is March 2011, as detailed in the next section.

In the South American sector at about $-15^{\circ}$ to $-20^{\circ}$ dip latitude, the probability of the formation of small-scale irregularities at the crests is maximum in the summer and the spring months (Alfonsi et al., 2013; Cesaroni et al., 2015; de Oliveira Moraes et al., 2018), when, during the post-sunset hours, the GNSS scintillation occurs almost daily. Conversely, such probability is lower during winter and, with a lesser extent, fall months. On average, during winter and fall, the bulk of the ionization is located at lower magnetic latitude than $-15^{\circ}$ to $-20^{\circ}$ dip latitude, i.e., toward the magnetic dip equator, with respect to the position held in summer and spring, when the crest moves southward (Cesaroni et al., 2015).

In particular, we provide the time scale-dependency of the amplitude scintillation index under both disturbed and quiet geomagnetic conditions. In fact, one of the most important aspects of the radio amplitude scintillation is its scale-dependent behavior, emerging from the small-scale properties of the plasma medium, resulting into different statistical properties of the sampled signal (Wernik, 1997; Materassi et al., 2005; Materassi \& Mitchell, 2007).

The aim is to compare such multi-scale picture with the corresponding one derived from geomagnetic indices and Interplanetary Magnetic Field (IMF) parameters to catch potential similarities. To the scope, we adopt a recently introduced data analysis technique called "Adaptive Local Iterative Filtering (ALIF)" (Cicone et al., 2016b). ALIF is able to efficiently decompose nonstationary signals into components, here called Intrinsic Mode Components (IMCs) (Piersanti et al., 2018). Detailed description of the technique, of its capabilities and performance against other standard techniques is addressed in the recent literature (Cicone et al., 2016a, 2016b; Cicone \& Zhou, 2017; Cicone \& Zhou, 2018; Piersanti et al., 2018; Cicone, 2019; Cicone \& Dell'Acqua, 2019) and the basic principles are recalled in the next section.

\section{Data and methods}

The ionospheric scintillations are commonly monitored by means of special GNSS receivers that, thanks to a dedicated firmware, derive the main ionospheric parameters by sampling the amplitude and the phase of the signals at high rate, typically $50 / 100 \mathrm{~Hz}$. One of these receivers is operating since October 2010 in San Miguel de Tucumán. The location of the receiver and its field of view projected at the ionospheric height of $350 \mathrm{~km}$ and considering an elevation larger than $50^{\circ}$ are shown in Figure 1.

The special GNSS receiver is a GSV4004B GPS Ionospheric Scintillation TEC monitor (GISTM). The GSV4004B is based upon a Novatel OEM4 receiver equipped with a low phase noise Oven-Controlled Crystal Oscillator (OCXO). It is also provided of a dedicated firmware able to compute, from $50 \mathrm{~Hz}$ samples, the amplitude and the phase scintillation indices $\left(S_{4}\right.$ and $\sigma_{\varphi}$, respectively) from the GPS L1 (1575.42 MHz) signal (Van Dierendonck et al., 1993). The proposed study focuses on the amplitude scintillation index $S_{4}$ alone, estimated every minute for every satellite in view.

To both discuss the multi-scale properties of the amplitude scintillation and to represent the overall amplitude scintillation over San Miguel de Tucumán every minute, we consider an averaged $S_{4}$, as:

$$
\left|S_{4}(t)\right|=\frac{\left.\sum_{i} S_{4 i}^{\mathrm{vert}}(t)\right|_{\alpha>50^{\circ}}}{N}
$$

In equation (1), $N$ is the total number of satellites in view by the receiver with elevation $\alpha$ larger than $50^{\circ}$ at a time $t$ and $S_{4 i}^{\mathrm{vert}}(t)$ is the value of the $S_{4}$ recorded by the $i$ th satellite and projected to the vertical according to the following formula:

$$
S_{4 i}^{\mathrm{vert}}=S_{4 i} /(F(\alpha))^{\frac{p+1}{4}}
$$

in which $p$ is the phase spectral slope, here assumed to be $p=2.6$ (Spogli et al., 2009, 2013; Alfonsi et al., 2013), and $F(\alpha)$ is the obliquity factor defined by Mannucci et al. (1993): 


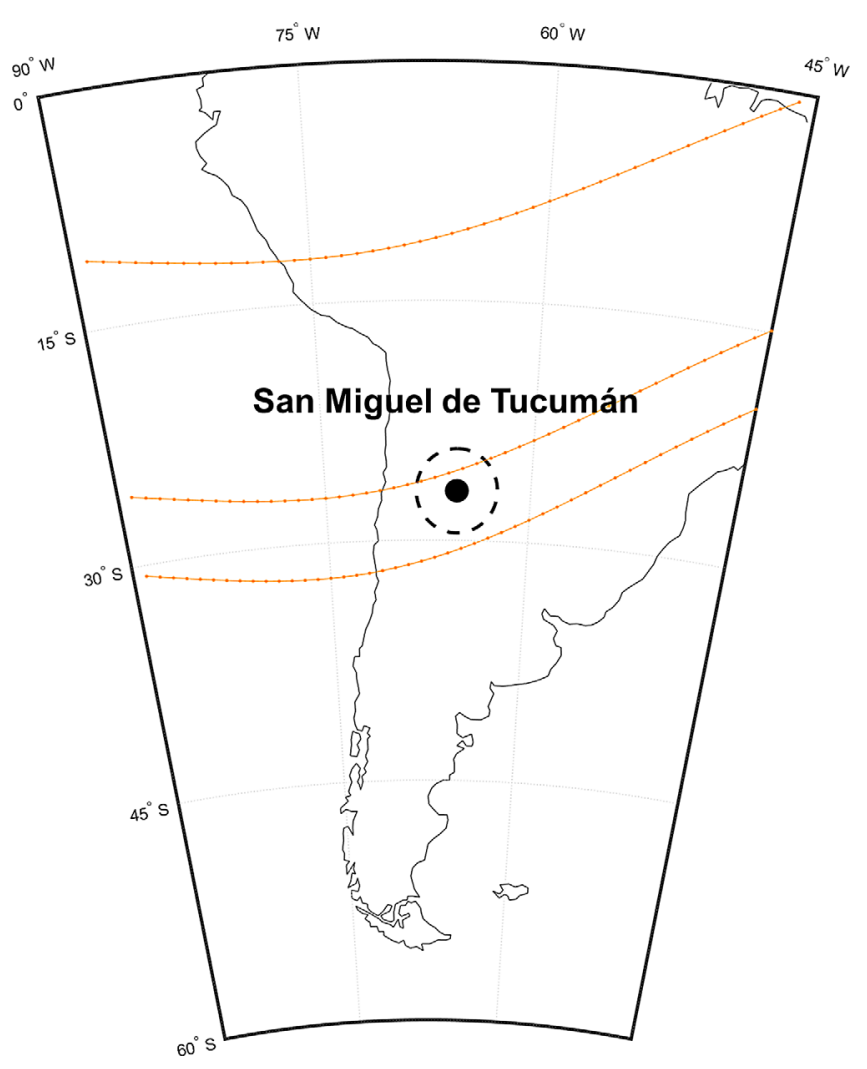

Fig. 1. Location (black dot) and field of view at $350 \mathrm{~km}$ for $50^{\circ}$ elevation (black dashed circle) of the GNSS receiver in San Miguel de Tucumán. Orange lines represent the expected position of the dip-equator on of the isoclinic lines at $-15^{\circ}$ and $-20^{\circ}$.

$$
F(\alpha)=\frac{1}{\sqrt{1-\left(\frac{R_{E} \cos \alpha}{R_{E}+H_{\mathrm{IPP}}}\right)^{2}}}
$$

In formula (3), $R_{E}$ is the Earth's radius and $H_{\mathrm{IPP}}$ is the altitude of the ionospheric pierce point, assumed to be located at $350 \mathrm{~km}$. The arbitrary threshold $\alpha>50^{\circ}$ in equation (1) is the best compromise to have both a continuous time series and a narrow field of view able to cover a single ionospheric sector. Details about strengths and weaknesses when using a verticalized scintillation index are discussed in Spogli et al. (2013). In other word, equation (1) defines the average of the $S_{4}$ values measured for each satellite in view above $50^{\circ}$ elevation. In analogy to Sanz et al. (2014) and Cherniak et al. (2014), this approach allows obtaining a single time series that we assume to represent the overall scintillation conditions on the receiver's overhead. In the remainder of the text, we will refer to $\left|S_{4}(t)\right|$ as $S_{4}(t)$ or simply as $S_{4}$, removing the time-dependency from the notation. As from Figure 1, the chosen elevation mask is able to make the overall scintillation index defined in equation (1) as a good proxy to depict the scintillation conditions in a narrow ionospheric sector located below the southern crest of the EIA.

The period taken into account is 1-31 March 2011, which was characterized by disturbed geomagnetic conditions in the first half of the month and quiet in the second one. The disturbed conditions were driven by a fast solar wind stream induced by a recurrent coronal hole hitting the Earth's magnetosphere during the early hours of 1 March 2011, resulting into a minor $(G 1)$ geomagnetic storm (minimum Dst $=-88 \mathrm{nT}$, maximum $K p=5$ ) that lasted approximately until the end of 6 March 2011. Signatures of significant auroral activity are present in the same days (maximum $\mathrm{AE}=882 \mathrm{nT}$ on 1 March at 14:00 UT). In addition, a Coronal Mass Ejection (CME) erupted on 7 March 2011 struck the magnetosphere on 10 March 2011 at around 06:30 UT. Such CME generated a moderate (G2) geomagnetic storm (minimum Dst $=-83 \mathrm{nT}$, maximum $K p=6-)$. The recovery phase of such storm lasted approximately until the end of 16 March 2011. The signatures of auroral activity were stronger than those recorded during the first storm (maximum AE = $1462 \mathrm{nT}$ on 11 March 2011 at 17:00 UT). The second half of the month was characterized by less disturbed conditions ( $K p \leq 4-$, Dst $\geq-18$ nT), with a weaker auroral activity, mainly recorded between 19 and 23 March 2011.

The analysis of the external drivers includes the z-component of the Interplanetary Magnetic Field (IMF-Bz), as measured by the Advanced Composition Explorer (ACE) satellite (Smith et al., 1998), the y-component of the Interplanetary Electric Field (IEF-Ey), derived from IMF by using also the solar wind (SW) velocity $v_{\mathrm{SW}}$ measured by the ACE (McComas et al., 1998). The indices of auroral activity AE and AL (Davis \& Sugiura, 1966) have been also considered to identify the level of disturbance of the auroral electrojet (AEJ), likely related to the penetrating electric fields phenomenon.

Moreover, time series of the variation of the geomagnetic field at the surface of the Earth due to the EEJ was obtained by taking the difference between the horizontal North-South (H) component of the geomagnetic field at a dip-equatorial station (latitude within $\pm 5^{\circ}$ ) and at an off-equatorial low-latitude station of the same longitude sector (e.g., Rastogi, 1989; Anderson, 2011). The stations used in this study are Kourou $\left(5.21^{\circ} \mathrm{N}, 307.26^{\circ} \mathrm{E}\right)$ and Isla de Pascua Mataveri-Easter Island $\left(27.1^{\circ} \mathrm{S}, 270.59^{\circ} \mathrm{E}\right)$.

In addition, to provide a proxy able to quantify if the energy input by each mode found in the solar wind parameter is efficiently brought into the magnetosphere, we consider also the epsilon ( $\varepsilon$ ) parameter, also known as "Akasofu parameter" (Perreault \& Akasofu, 1978; Akasofu, 1981; Akasofu, 1996). In the SI units, the $\varepsilon$ parameter is defined as:

$$
\varepsilon(W)=\frac{4 \pi}{\mu_{0}} v B^{2} \sin ^{4}\left(\frac{\theta}{2}\right) l_{0}^{2}
$$

in which $\left(v B^{2} / \mu_{0}\right)$ is the Poynting flux per unit area, $\theta$ is the IMF clock angle $(\tan \theta=\mathrm{IMF}-\mathrm{By} / \mathrm{IMF}-\mathrm{Bz})$ and $l_{0}$ is a scaling factor determined empirically. As we consider time series of the $\varepsilon$ parameter for long periods, we adopt the value $l_{0}=7 \mathrm{R}_{\mathrm{E}}$ as reported in Koskinen \& Tanskanen (2002).

Time profiles of $S_{4}$, of auroral activity indices, of $\mathrm{Kp}$ and Dst, of IEF-Ex, of IMF-Bz, of EEJ and of $\varepsilon$ parameter for March 2011 are reported in Figure 2.

In order to study its multi-scale proprieties, $S_{4}(t)$ has been decomposed using ALIF (Cicone et al., 2016b; Piersanti et al., 2018). As a signal decomposition analysis, ALIF inherits from the Empirical Mode Decomposition Technique (EEMD) (Huang et al., 1998). ALIF improves EEMD technique by 


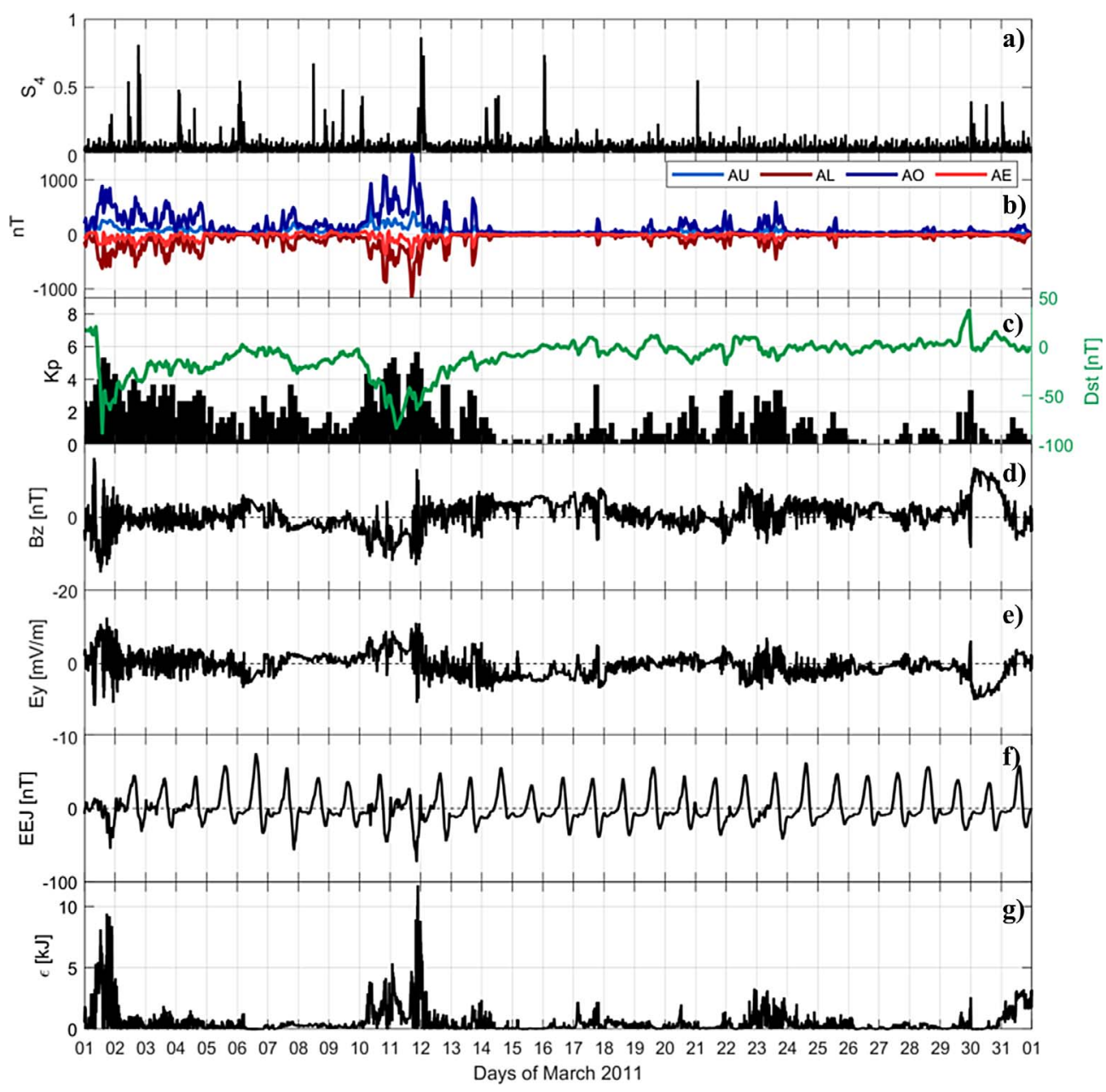

Fig. 2. Time profiles of (a) $S_{4}$, (b) auroral activity indices, (c) Kp and Dst, (d) IMF-Bz, (e) IEF-Ey, (f) EEJ and (g) Akasofu ( $\varepsilon$ ) parameter for March 2011.

relying on a stronger mathematical basis that ensures the convergence and stability of the algorithm (Cicone \& Zhou, 2018). In addition, ALIF overcomes the issues related by traditional signal decomposition techniques, such as the limited resolution (Cohen, 2001) and interferences in the time-frequency domain (Flandrin, 1998). As stated in the previous section, ALIF decomposes a given signal into functions (IMCs) oscillating around zero, each of them characterized by its frequency/ period. Then, the time series of $S_{4}(t)$ defined by equation (1) has been decomposed along IMCs $S_{4 l}(t)$, in which $l$ indicates its period, being its peculiar time scale of variability (multi-scale decomposition):

$$
S_{4}(t)=\sum_{l}^{N_{\mathrm{IMC}}} S_{4 l}(t)+S_{4 \mathrm{res}}(t)
$$

In equation (5), $N_{\text {IMC }}$ is the total number of IMCs of the considered time series and $S_{4 \text { res }}$ is the residual obtained by subtracting the sum of all the computed IMCs from the original signal. Thus, $S_{4 l}(t)$ represents the component of the $S_{4}$ time series having characteristic period $l$. In our analysis, the time is always referred to the universal time (in San Miguel de Tucumán, $\mathrm{LT}=\mathrm{UT}-4)$.
ALIF has been proved to be efficient in separating different scales, allowing to make a scale-by-scale comparison among different signals coming from different sources, such as solar wind, magnetosphere and ionosphere (Bertello et al., 2018; Piersanti et al., 2018). The multi scale analysis can then reveal interesting features of the solar wind-magnetosphereionosphere (SW-M-I) coupling, including the modification of the electrodynamics of the low latitude ionosphere. The effectiveness of ALIF in disentangling regular from irregular variations in the investigated parameter is the key aspect of the proposed study.

Before exposing the results of our work, a crucial clarification is needed. Thanks to the decomposition (Eq. (5)), we can make a quantitative comparison between time series of the $l$ th component of a helio-geophysical proxy $\left(X_{l}(t)\right)$, being the "cause" of the $S_{4}$ variability and of the $l$ th component of $S_{4}$ $\left(S_{4 l}(t)\right)$, being the "effect". Since $X_{l}(t)$ and $S_{4 l}(t)$ are both decomposed into IMCs, we assume that the $l$ temporal scale of the cause drives the same-l temporal scale of the effect or at least that this stands for range of comparable periods. In simpler words, we compare the ranges of period $l$ to speculate about cause-effects mechanisms that could lead to the recorded amplitude scintillation. As the phenomena involved in each step of 

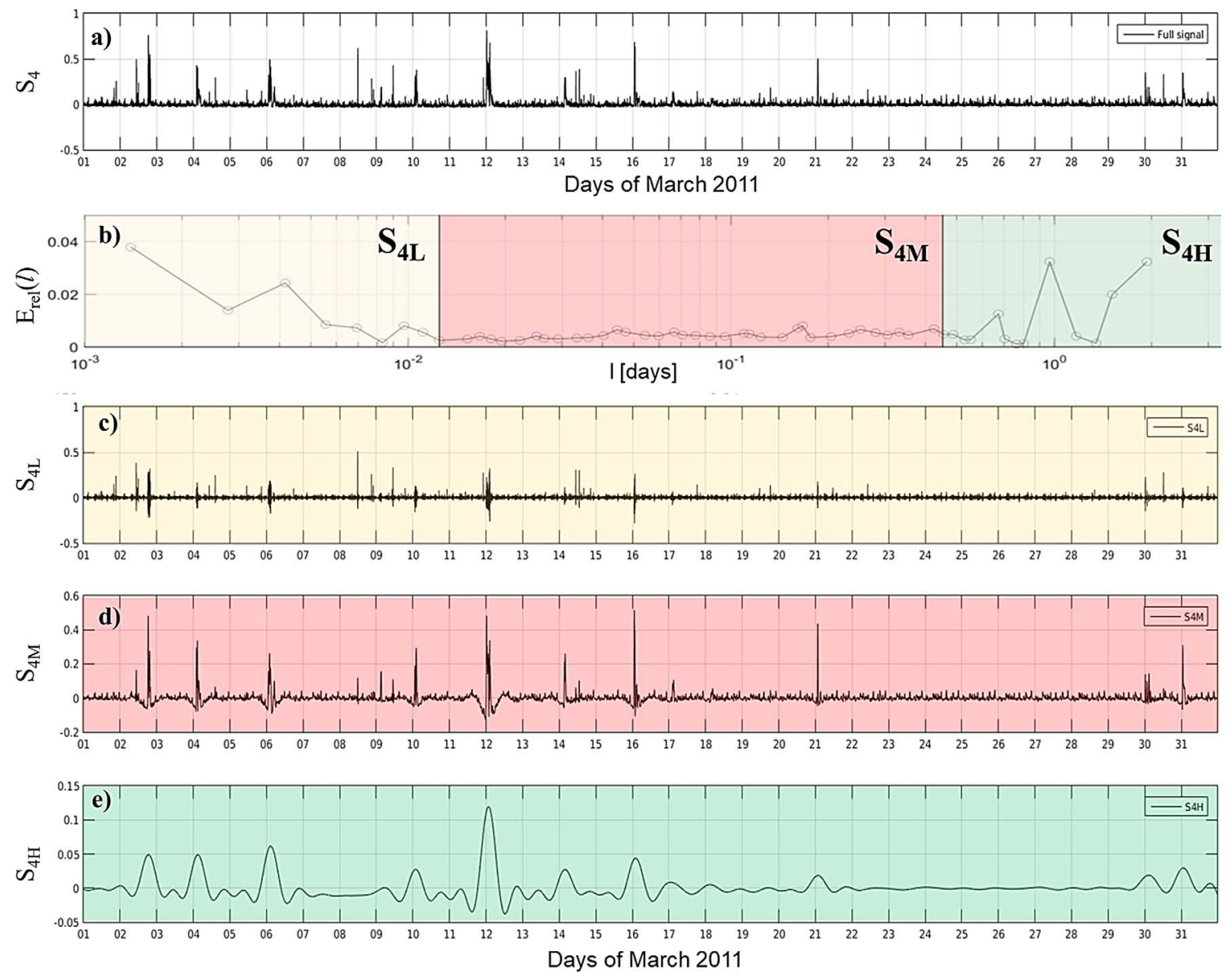

Fig. 3. (a) $S_{4}$ time profile over San Miguel de Tucumán during March 2011. (b) Relative energy of each intrinsic mode component of the $S_{4}$ index as a function of the period (in days); colors indicate three different intervals of periods: low periods (yellow), middle periods (red) and high periods (green). (c-e) Report the time profiles of the sum of the $S_{4}$ intrinsic mode components of the low $\left(S_{4 \mathrm{~L}}\right)$, middle $\left(S_{4 \mathrm{M}}\right)$ and high $\left(S_{4 \mathrm{H}}\right)$ periods, respectively.

the cause-effect chain ruling the SW-M-I coupling are assumed to have typical lifetimes smaller than the relaxation time of the system as a whole, one may assume implicitly that the SW-M-I system is not characterized by accumulation, hysteresis or memory mechanisms. This might not be true in general terms, as some have questioned (see, e.g., Consolini et al., 2005). Still, we have supposed memory effects to be negligible in this case.

\section{Results}

Figure 3a shows $S_{4}(t)$ over San Miguel de Tucumán during the whole March 2011. The scintillation found in correspondence with the geomagnetic storm, having its commencement on 10 March 2011, have been also addressed in Alfonsi et al. (2013), in which also its relationship with several types of Spread-F, recorded by a co-located ionosonde, is highlighted and discussed in detail.

The peaks in the time profile (Fig. 3a) depict the amplitude scintillation to take place roughly "once per day", mainly during the first half of the month. This is likely due to the disturbed conditions induced by the two storms occurring in the first half of the month that may result into a mapping of the EPB above
San Miguel de Tucumán. Along the considered period, there is an alternation between days with and without scintillation, and we would like to characterize these changes with the proposed multi-scale approach.

Figure $3 \mathrm{~b}$ reports the relative energy $E_{\text {rel }}(l)=$ $\left.\left.<S_{4 l}^{2}\right\rangle /<S_{4}^{2}\right\rangle$ (being $\langle\cdots\rangle$ a time average) of each IMC $\mathrm{S}_{4 l}$ as a function of the ALIF-equivalent period $l$ expressed in days. The values of $E_{\text {rel }}$ provide the relative weight of the energy budget of the single IMC with respect to the overall energy (integrated over all time scales). This indicates how the single time scale is significant with respect to the others (see, e.g., Bertello et al., 2018; Piersanti et al., 2018). We notice that IMCs having a difference in frequency below $10^{-5} \mathrm{~Hz}$ are considered as a single IMC and merged. The trend term is removed from the analysis and is not considered hereafter. Then, the obtained number of meaningful IMCs is $N_{\text {IMC }}=57$.

The behavior of $E_{\text {rel }}(l)$ is characterized by larger values at low and high periods, while a plateau is present in the middle of the spectrum. According to this behavior, we define three different ranges of $l$, according to Table 1 .

Figure 3c-e shows the reconstruction of $S_{4 \mathrm{~L}}, S_{4 \mathrm{M}}, S_{4 \mathrm{H}}$, as the sum of the IMCs corresponding to the low, middle and high regimes, respectively: 
Table 1. Range of periods and corresponding IMCs.

\begin{tabular}{llc}
\hline Name & \multicolumn{1}{c}{ IMCs } & Periods \\
\hline Low periods (L) & From IMC1 to IMC9 & $l<28.8 \mathrm{~min}$ \\
Middle periods (M) & From IMC10 to IMC44 & $28.8 \mathrm{~min} \leq l<10.8 \mathrm{~h}$ \\
High periods (H) & From IMC45 to IMC57 & $l \geq 10.8 \mathrm{~h}$ \\
\hline
\end{tabular}

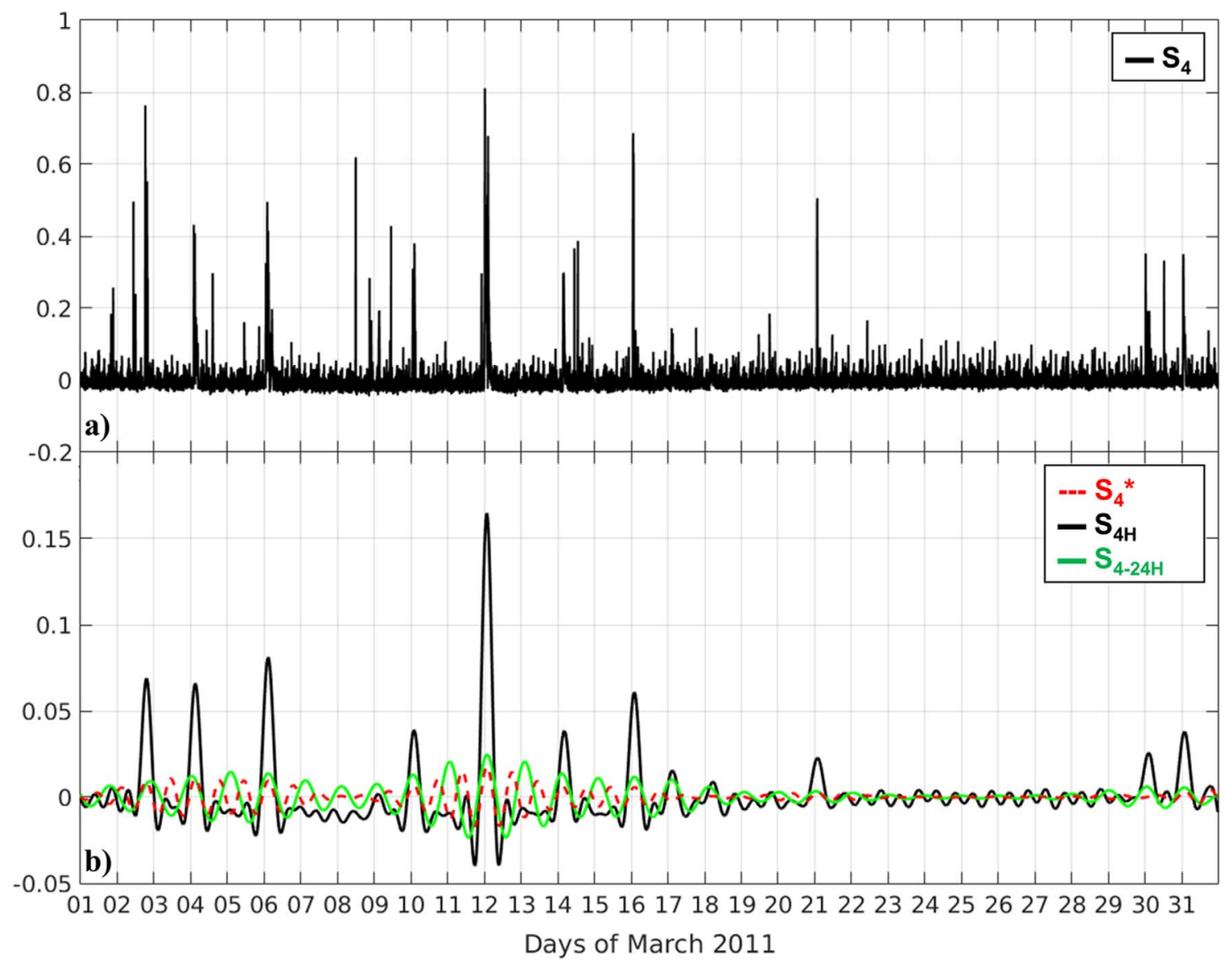

Fig. 4. (a) Same as Figure 2a. (b) Time profile of $S_{4 \mathrm{H}}$ (black solid line), $S_{4-24 \mathrm{H}}$ (green solid line), being the intrinsic mode component having 1-day period, and $S_{4}^{*}$ (red dashed line).

$$
\left\{\begin{aligned}
S_{4 L}(t) & =\sum_{\mathrm{IMC1}}^{\mathrm{IMC} 9} S_{4 l}(t) \\
S_{4 M}(t) & =\sum_{\mathrm{IMC} 10}^{\mathrm{IMC} 44} S_{4 l}(t) \\
S_{4 H}(t) & =\sum_{\mathrm{IMC} 45}^{\mathrm{IMC} 57} S_{4 l}(t)
\end{aligned}\right.
$$

We notice the reader that the proposed multi-scale analysis decomposes the $S_{4}$ time series, positive by definition, into IMCs that present negative values. Such negative values are because the baseline of the considered time series is not zero and $S_{41}$ 's are fluctuations around such baseline. Despite the meaningless of the negative values, the decomposition allows quantifying the relative importance of each modes composing the total $S_{4}$ time series.
Since we are investigating the formation of the small-scale irregularities embedded in the post-sunset EPBs and resulting into a day-to-day variability of the scintillation, we concentrate on the $S_{4 \mathrm{H}}$, alone, i.e., for periods larger than $10.8 \mathrm{~h}$. As from Figure $3 b$, we are aware that the study of the low-periods regime is of great interest to understand the dynamics of the scintillation triggering, but it is out of the scopes of this paper and worth of a dedicated paper.

Thus, the 24-hour component $S_{4 \_ \text {IMC53 }}(t)=\mathrm{S}_{4-24 \mathrm{H}}(t)$ has been isolated from the other IMCs of the high-periods regime and $S_{4} *$ has been defined as the sum of all IMCs of the high period components having periods strictly less than 24-hour. We let the reader notice that the relative energy of the 24-hour and of its harmonic at 48-hour are the most energetic, indicating that the "once-per-day scintillation" is energetically meaningful and that it is the principal effect at ground in the characterization 


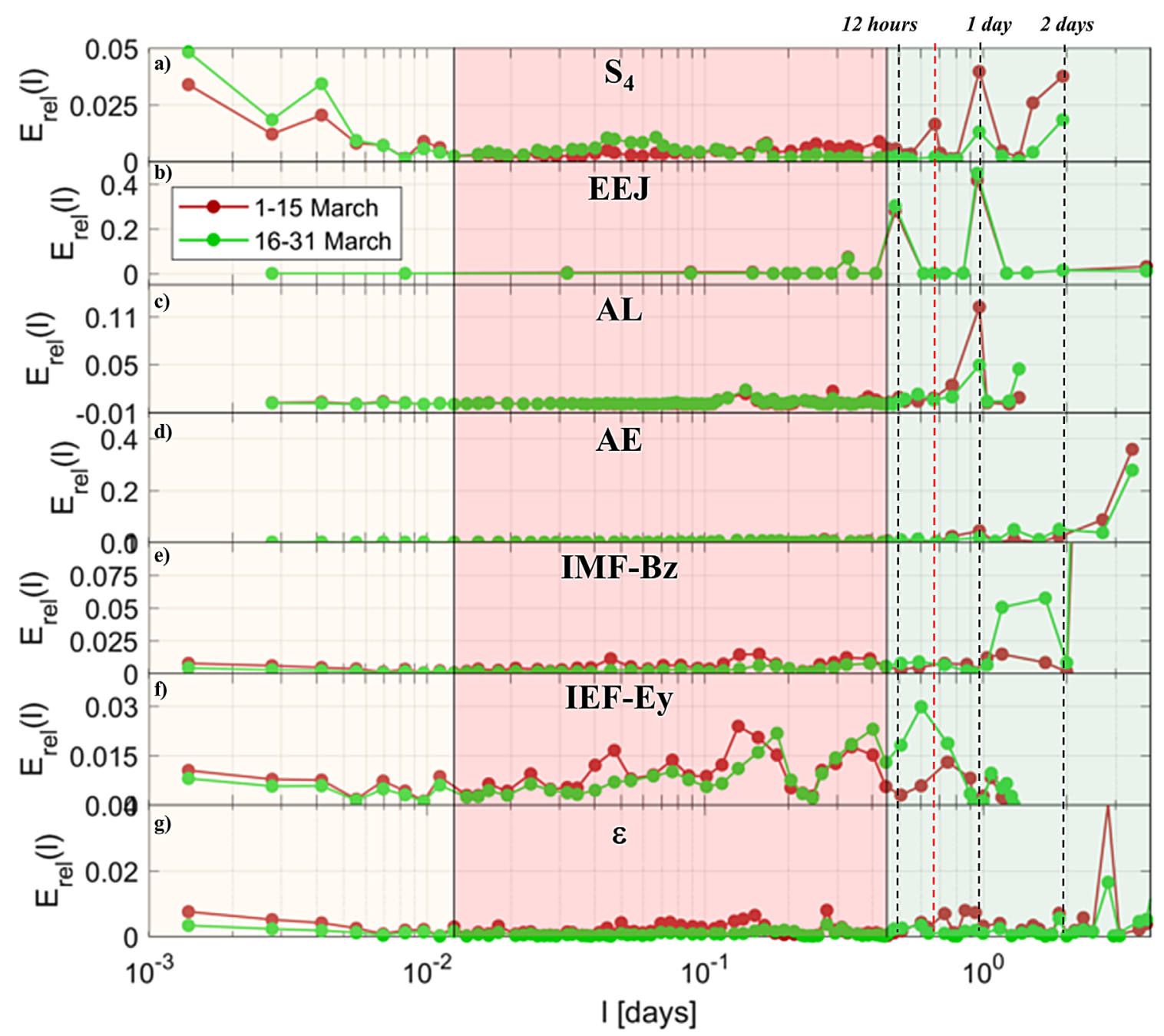

Fig. 5. Relative energy of each intrinsic mode function as a function of the period (in days) calculated for (a) $S_{4}$, (b) Equatorial Electrojet, (c) AL index, (d) AE index, (e) IMF-Bz, (f) IEF-Ex and (g) $\varepsilon$ parameter. Red curves are for 1-15 March 2011, while green curves for the period 16-31 March 2011. Similarly to Figure 3, shaded colors (yellow, red, green) indicate three different intervals of periods: low periods (yellow), middle periods (red) and high periods (green). Black dashed lines indicate $12 \mathrm{~h}, 1$ day and 2 days, respectively, while the red-dashed line is in correspondence with $18 \mathrm{~h}$.

of the scintillation under the crests of the EIA. The presence of the 48-hour components, and of components with $l>1$ day in general, is an intriguing feature, that deserves further assessment and consolidation with accumulated statistics. The present case allows only tentative speculations. It may indicate that the presence of the scintillation is a phenomenon involving only the day in which it occurs, but it has somehow a sort of hysteresis, that modulates the scintillation patterns. Furthermore, the 48-hour component could be influenced by the 2-day oscillation of the EIA due to planetary waves modulating the tidal wind (Chen, 1992).

Figure 4 reports the superposition of $S_{4} *, S_{4 \mathrm{H}}$ and $S_{4-24 \mathrm{H}}$. Doing so, we try to single out those features of the long period fluctuations not due to the "regular" post-sunset phenomena giving rise to EPBs: $S_{4} *(t)$ should then represent the time series of perturbations to the regularity of post-sunset scintillation. The most intriguing feature is that the phase difference between
$S_{4-24 \mathrm{H}}$ and $S_{4} *$ seems to result into constructive and destructive interference, enhancing or suppressing $S_{4 \mathrm{H}}$, respectively.

The interplay between $S_{4} *$ and $S_{4-24 \mathrm{H}}$ leads to a meaningful enhancement of $S_{4 \mathrm{H}}$ between 11 and 12 March 2011, also in correspondence with the peak of the auroral activity and with the absence of scintillation during the recovery and peak phases of the March G1 and G2 storms. Thus, the IMCs found in the high period range hours (except for the components having $l \geq 24 \mathrm{~h}$ ) create a modulation of the 24-hour component, leading to the intensification/depletion of the scintillation activity.

To speculate on the role of the helio-geophysical proxies found in the IMCs of $S_{4}$ and, in particular, on how temporal scales found in the proxies drive the same temporal scale(s) of the effect, we separate the considered datasets in the first (1-15) and second (16-31) half of March 2011. This allows comparing between disturbed (1-15 March) and quiet (16-31) conditions of the geospace. 


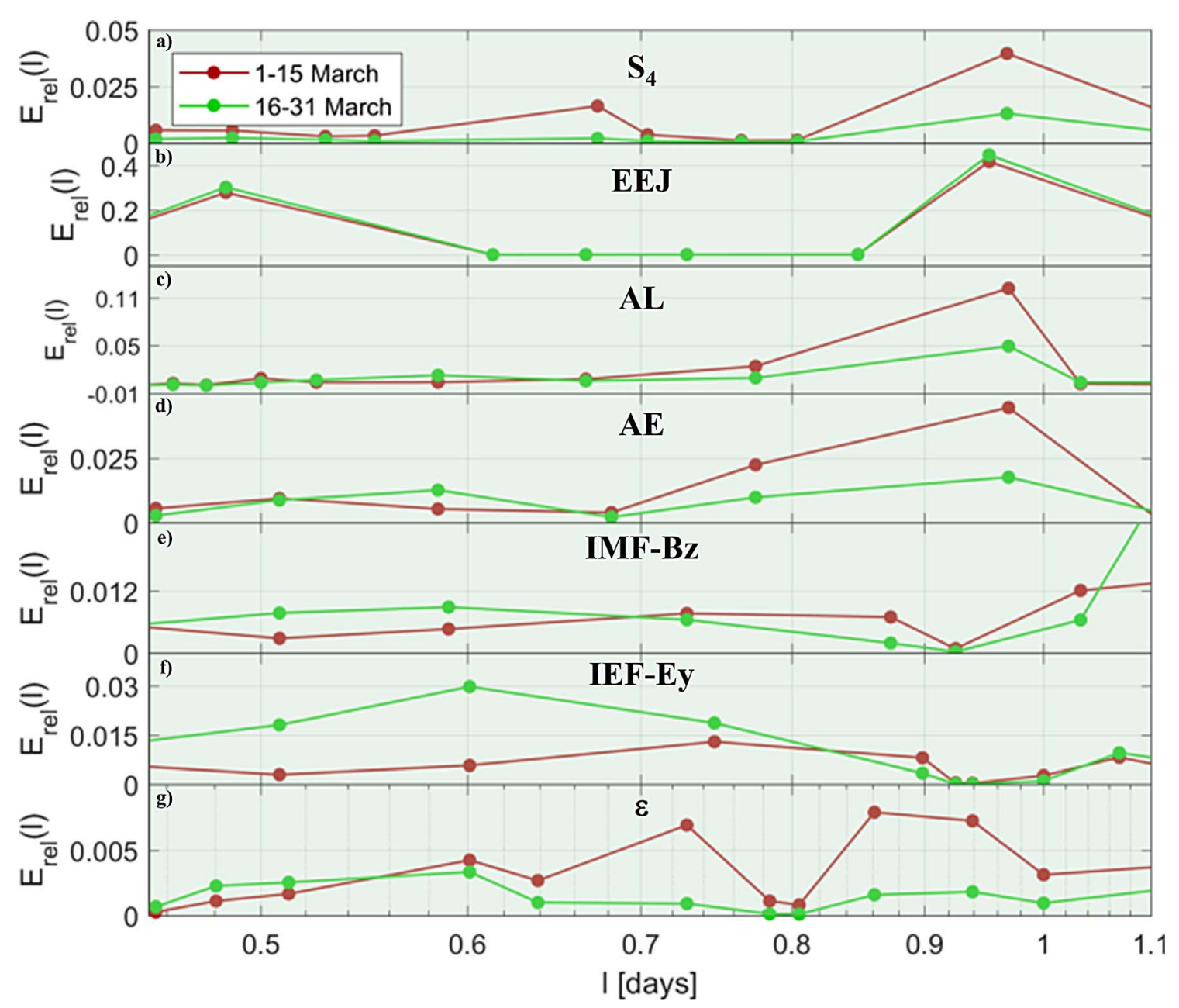

Fig. 6. Zoom of Figure 5 in the high-period range, up to 1.1 days.

Similarly to Figure $3 b$, Figure 5 shows the relative energy $E_{\text {rel }}$ of each IMC as a function of the period calculated for $S_{4}$ [(a), same of Fig. 3b], EEJ (b), AL index (c), AE index (d), IMF-Bz (e), IEF-Ey (f) and $\varepsilon$ parameter (g). Red curves are for 1-15 March, while green curves for 16-31. Similarly to Figure $3 \mathrm{~b}$, colors indicate three different intervals of periods: low periods (yellow), middle periods (red) and high periods (green). To better highlight the features of the IMCs found for all the investigated quantities, a zoom in the high-period range up to 1.1 days has been provided in Figure 6. We let the reader notice that the set of frequencies/periods of the IMCs is the same for quiet and disturbed conditions, as we first decomposed the signal by considering the datasets for whole March 2011, and then we separated the IMCs according to the first and second half of the month. This allows a mode-to-mode comparison, focusing on IMCs intensification or depletion under quiet and disturbed conditions.

It is interesting to note that for $S_{4}$, the relative energy of the IMCs in the high period regimes is generally larger for disturbed conditions than for quiet conditions. For both geospace conditions, the IMC at 1 day and its harmonics at 2 days are present. The most intriguing difference is the intensification of the IMC at $16.3 \mathrm{~h}$ (red dashed line in Fig. 5), that is characterized by a larger $E_{\text {rel }}$ with respect to the other IMCs in the range $10.8 \mathrm{~h}$ to 1 day. As already visible in Figure $3 \mathrm{~b}$, the IMCS at $16.3 \mathrm{~h}$ is the most energetic component of $S_{4}^{*}$, being responsible for the already highlighted constructive and destructive interference, enhancing or suppressing $S_{4 \mathrm{H}}$, respectively.

Concerning the helio-geophysical proxies, it is interesting to note that the modes at $l=0.5$ days and $l=1$ day are clearly present for the EEJ in both quiet and disturbed conditions. This is an expected feature of the low-latitude ionosphere, well depicted by ALIF, as it represents the daily changes of the EEJ at the passage of the solar terminator. This is another proof of the reliability of the technique in providing useful information on geophysical signals. The $E_{\text {rel }}$ of the EEJ modes for quiet and disturbed days almost overlap. In the high-periods regime, small differences are found for $l=0.5$ days and $l=1$ day, for which disturbed periods have slightly lower relative energies than the quiet ones, and for $l=4$ days for which the vice-versa stands. This may indicate that the disturbance does not affect the presence of the diurnal and semidiurnal variations of the EEJ, which is mainly driven by the photoionization and neutral winds circulation in the thermosphere.

Concerning the auroral indices, under disturbed conditions, the 24-hour component is the most energetic and in both $A E$ and $A L$ signatures. Beside the 24 -hour, the component at 0.78 days $(18.7 \mathrm{~h})$ is the one which shows larger differences between quiet 


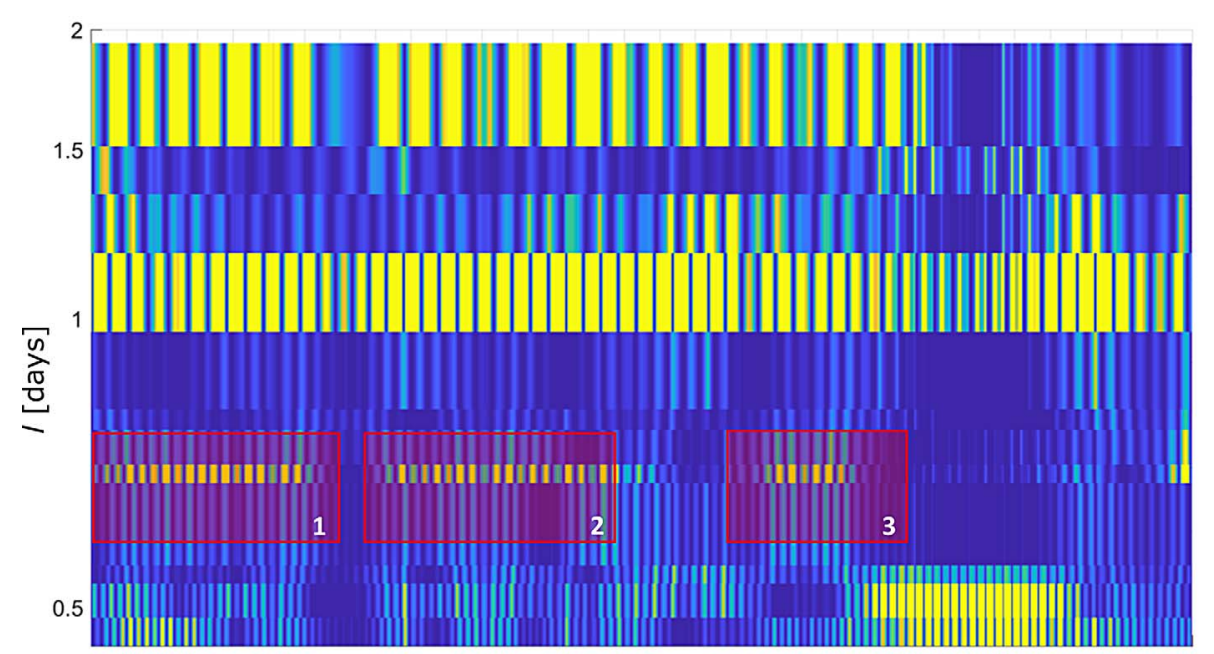

a) 0102030405060708091011121314151617181920212223242526272829303101 Days of March 2011

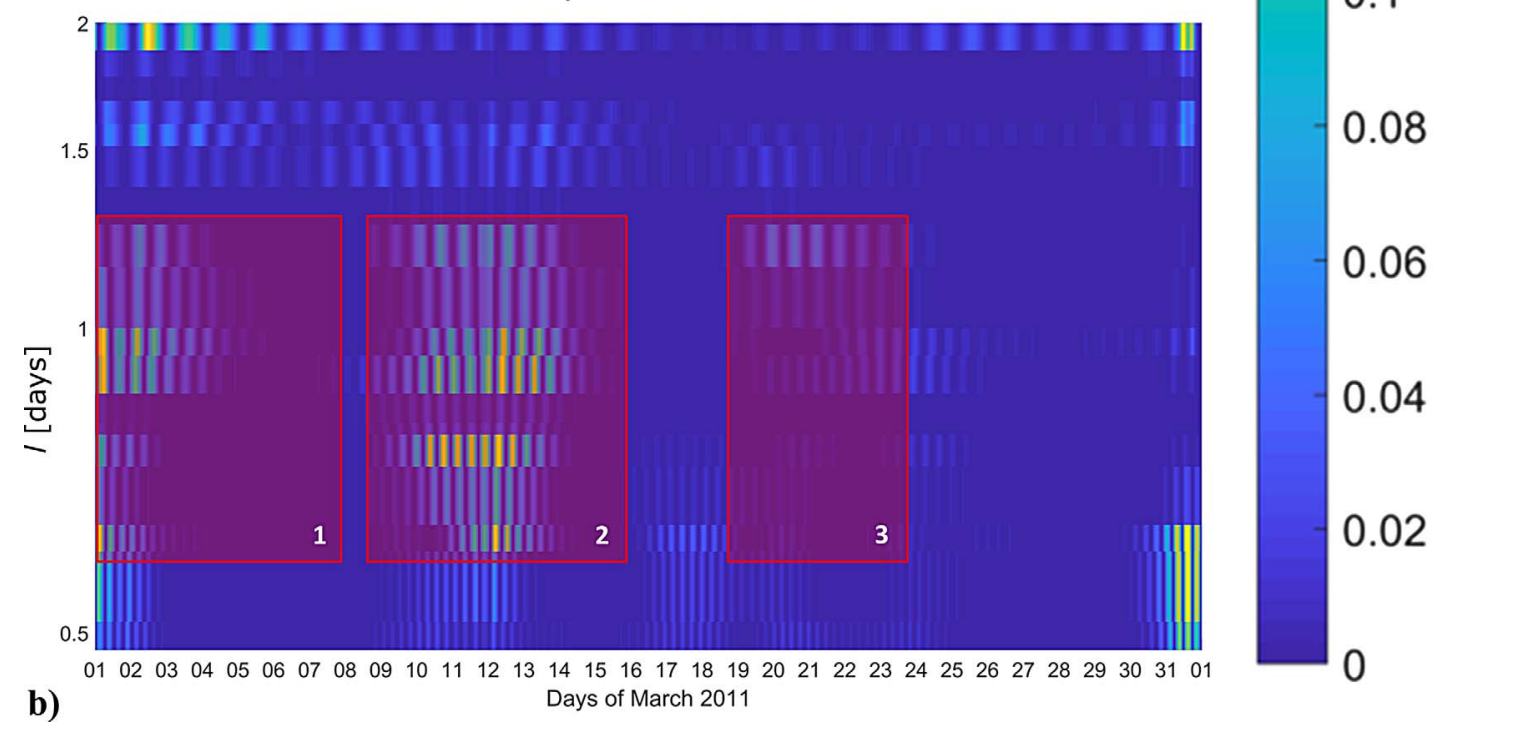

Fig. 7. Instantaneous (1-min) relative energy of each intrinsic mode function of (a) $S_{4 \mathrm{H}}$ and (b) $\varepsilon$ parameter for 1-31 March 2011 .

and disturbed days. The westward AEJ, whose intensity is parametrized by $\mathrm{AL}$, is one of the key parameters to measure the geoeffectiveness of the penetration of the interplanetary electric field during magnetic substorms (see, e.g., Lyatskaya et al., 2009).

According to panels e and d of Figures 5 and 6, for what concerns the IMF-Bz, no meaningful distinction between disturbed and quiet times is found for $l<1$ day, while for IEF-Ey, the relative energy of the IMCs in the high-period range, up to 1.1 days, is significantly larger during quiet times than during disturbed ones.

Conversely, it is worth noticing that the relative energy of the $\varepsilon$ parameter under disturbed conditions (Fig. $5 \mathrm{~g}$ ) indicates that the modes between $l=0.5$ days and $l=1$ day are in general more energetic than for quiet conditions. Namely, two meaningful increases of $E_{\text {rel }}$ occur at 0.72 days $(17.3 \mathrm{~h})$ and between 0.86 days $(20.6 \mathrm{~h})$ and 1 day. In the same range of periods, the $E_{\text {rel }}$ corresponding to quiet times shows similar behaviour but significantly lower values. This allows speculating that the modes present in the solar wind during disturbed conditions may be more effective in transferring energy from the solar wind into the magnetosphere than under quiet conditions. This somehow confirms what is known, although highlighting what are the resonant modes through which the transfer of energy is made.

This may suggest that the found $\varepsilon$ parameter IMCs in the same period range $(0.5<l<1$ days) are energetically meaningful too and may result into the corresponding IMCs of the $S_{4}$ signal, as stated above.

To highlight the correlation between $S_{4}$ and the energy input from the solar wind, Figure 7 reports the instantaneous (1-min) relative energy of each intrinsic mode function of the $S_{4}$ (a) and $\varepsilon$ parameter (b) as a function of the day of March 2011.

Focusing on the IMF characterized by $l=16.3 \mathrm{~h}$, it enhances two times (\#1 and \#2) during the first half of the month, as highlighted by the red-shadowed boxes labeled as 1 and 2 in Figure 7. A third intensification is found also in the second half of the month, as highlighted by the red-shadowed boxes labeled as 3 . 
In correspondence of enhancements \#1 and \#2, the $E_{\mathrm{rel}}$ of the $\varepsilon$ parameter for $l=0.72$ days $(17.3 \mathrm{~h})$ and $l$ between 0.86 days $(20.6 \mathrm{~h})$ and 1 day are enhanced slightly in advance. For what concerns enhancement \#3, no meaningful intensification $e$ parameter at $l=0.72$ days is found, but only with less intensity in the range between 0.86 days $(20.6 \mathrm{~h})$ and 1 day. A small role seems to be also played by IMCs having $1<l<1.5$ days, as their $E_{\text {rel }}$ values slightly enhance, but with lower intensity than at 0.72 days and between 0.86 and 1 days.

\section{Conclusions}

In this work, we propose a novel approach to investigate the cause-effect mechanism ruling the occurrence of GNSS scintillation in the low-latitude ionosphere. Such approach allows highlighting that some helio-geophysical parameters may be characterized by oscillating modes that somehow influence, or better modulate, the scintillation patterns found at ground.

Leveraging on the fine decomposition of geophysical signals provided by the ALIF technique, the multi-scale statistical properties of the amplitude scintillation could be unveiled and correlated with the parameters describing the conditions of the near-Earth environment. The GNSS signals acquired over San Miguel de Tucumán are excellent probes to investigate the scintillation inhibition/enhancement under storm conditions and the day-to-day variability below the southern crest of the EIA. Such approach is here tested by using the $S_{4}$ data recorded during the March 2011, whose first half is characterized by two geomagnetic storms and it is assumed to be representative of the disturbed conditions, while the second half is characterized by generally quiet conditions.

Building up an overall $S_{4}$ index for the station, we highlighted three different ranges of periods $l$ : low $(l<28.8 \mathrm{~min})$ and high periods $(l \geq 10.8 \mathrm{~h})$ are characterized by increased values of the relative energy of the $S_{4}$ modes, while a plateau is present in the middle of the spectrum. This can be interpreted as the low-periods regime relates to the triggering of the scintillation, whereas the high-periods regime relates with its day-to-day variation.

The focus of this work is on the high-periods regime, to speculate about the cause-effect mechanisms leading to appearance and enhancement/inhibition of the post-sunset scintillation.

According to Figure 3b, the 24-hour component is the most energetic of the high-period regime, confirming that the scintillation pattern found along the month of March is mainly driven by the post-sunset EPB, found to map over Tucumán during the considered period.

By considering an $S_{4 \mathrm{H}}$ as the sum of all modes in the highperiods regime, the day-to-day appearance of scintillation is found to be modulated by the interplay between the 24-hour component $\left(S_{4 \_24 \mathrm{H}}\right)$ and the sum of all the remaining components in the range period $10.8 \mathrm{~h}<l<1$ day $\left(S_{4} *\right)$. In this range, the most energetic mode is $l=16.3 \mathrm{~h}$. The phase difference among such components modulates the dependence of the scintillation appearance during post-sunset hours. By comparing disturbed and quiet times, the $l=16.3 \mathrm{~h}$ mode is energetically depleted during quiet times, while it peaks during disturbed times. No meaningful difference in the energy of the $l=1$ day mode is found between the quiet and disturbed conditions.
This reinforces the idea that the external forcing due to harsh geospace conditions leads to the intensification of the modes between $10.8 \mathrm{~h}$ and 1 day (excluded) and of the at $l=16.3 \mathrm{~h}$ mode. For this reason, we analyze the main helio-geophysical parameters to look for modes of a compatible range of periods.

Among the investigated parameters, the Akasofu's $\varepsilon$ parameter is considered, being a measure of the energy input from the solar wind parameter into the magnetosphere. Such parameter is characterized by modes in the range of periods between $10.8 \mathrm{~h}$ and 1 day. The modes at $l=0.72$ days $(17.3 \mathrm{~h})$ and $l$ between 0.86 days $(20.6 \mathrm{~h})$ and 1 day are significantly larger during disturbed than quiet times. By looking at their instantaneous relative energy along the whole March 2011, we highlighted also how the intensification of the above mentioned modes is found in correspondence with the intensification of scintillation mode at $l=16.3 \mathrm{~h}$. As expected from the cause-effect chain, the intensification of the $\varepsilon$ parameter identified modes precedes the intensification of the scintillation mode. This may highlight how solar wind fluctuations of such modes appear to anticipate the corresponding modes of radio scintillation, pointing toward a causal relationship, mediated by those resonant modes.

By investigating the other helio-geophysical parameters, we also derived more intriguing features. Namely, we found the modes at $l=12 \mathrm{~h}$ and $l=1$ day as the most energetic for the EEJ measurement. This is in agreement with the semi-diurnal changes in the EEJ at the passage solar terminator. Moreover, the energy of the two modes is almost comparable between quiet and disturbed days. This is somehow reasonable, as the disturbance does not affect the presence of the modes, i.e., the solar terminator effect always dominates.

Concerning the auroral indices, under disturbed conditions, an intensification of the modes at 1 day and $18.7 \mathrm{~h}$ is found. In addition, the same signature in the auroral activity in the range $10.8 \mathrm{~h}<l<1$ day modes is found. This may be related to the fact that the increased AL/AE is a direct signature of the geoeffectiveness of the penetration of the interplanetary electric field during magnetic substorms (see, e.g., Lyatskaya et al., 2009).

An outstanding issue is the behavior of the found modes for the interplanetary magnetic and electric fields. In fact, unexpectedly the modes of the two fields are generally lower during disturbed than quiet times, while the contrary stands in the mid-periods $(28.8 \mathrm{~min} \leq l<10.8 \mathrm{~h}$ ) regime.

Our analysis shows how the time-frequency structure of the amplitude scintillation on GNSS signals can be characterized in terms of the resonant modes found in the combination of the Akasofu parameter. When assessed statistically, the proposed study may pave the way to the development of models driven by interplanetary parameters aimed at characterizing the scintillation on L-band signals. The detection of resonant modes in the identified parameters can be used to define the Space Weather impact on GNSS signals recorded at ground.

Acknowledgements. Authors are grateful to Dr. Miguel Cabrera for the support in the installation and the maintenance of the GNSS receiver in San Miguel de Tucumán. Scintillation data are available at the eSWua website (http://eswuax. rm.ingv.it/). ALIF software is available at www.cicone.com. Auroral indices data are available at the World Data Center for Geomagnetism of Kyoto (http://wdc.kugi.kyoto-u.ac.jp/). Solar Radio Flux $(10.7 \mathrm{~cm})$ data are provided by the Natural 
Resources Canada (http://www.spaceweather.gc.ca/solarflux/ sx-5-mavg-en.php). Interplanetary magnetic field and solar wind data are provided by Coordinated Data Analysis Web (CDAWeb, https://cdaweb.sci.gsfc.nasa.gov). The authors also thank the Italian Space Agency (ASI) for the financial support under the contract ASI "LIMADOU scienza" $n^{\circ}$ 2016-16-H0. The editor thanks two anonymous referees for their assistance in evaluating this paper.

\section{References}

Aarons J. 1991. The role of the ring current in the generation or inhibition of equatorial $\mathrm{f}$ layer irregularities during magnetic storms. Radio Sci 26(4): 1131.

Abdu MA. 2005. Equatorial ionosphere-thermosphere system: Electrodynamics and irregularities. Adv Space Res 35(5): 771-787.

Abdu MA, Kherani EA, Batista IS, Sobral JHA. 2009. Equatorial evening prereversal vertical drift and spread F suppression by disturbance penetration electric fields. Geophys Res Lett 36: L19103. DOI: 10.1029/2009GL039919.

Akasofu SI. 1981. Energy coupling between the solar wind and the magnetosphere. Space Sci Rev 28(2): 121-190.

Akasofu S-I. 1996. Search for the "unknown" quantity in the solar wind: A personal account. J Geophys Res 101: 10531-10540.

Alfonsi L, Spogli L, Tong JR, De Franceschi G, Romano V, Bourdillon A, Le Huy M, Mitchell CN. 2011. GPS scintillation and TEC gradients at equatorial latitudes in April 2006. Adv Space Res 47(10): 1750-1757.

Alfonsi L, Spogli L, Pezzopane M, Romano V, Zuccheretti E, De Franceschi G, Cabrera MA, Ezquer RG. 2013. Comparative analysis of spread-F signature and GPS scintillation occurrences at Tucumán, Argentina. J Geophys Res Space Phys 118: 4483-4502. DOI: 10.1002/jgra.50378.

Anderson D. 2011. Daytime vertical $\mathrm{E} \times \mathrm{B}$ drift velocities inferred from ground-based equatorial magnetometer observations. In: Aeronomy of the Earth's atmosphere and ionosphere, Abdu MA, Pancheva D, Bhattacharyya A (Eds.), Springer, The Netherlands, vol. 2, pp. 203-210. DOI: 10.1007/978-94-007-0326-1.

Astafyeva E, Zakharenkova I, Patrick A. 2016. Prompt penetration electric fields and the extreme topside ionospheric response to the June 22-23, 2015 geomagnetic storm as seen by the Swarm constellation. Earth Planets Space 68(1): 152.

Bertello I, Piersanti M, Candidi M, Diego P, Ubertini P. 2018, October. Electromagnetic field observations by the DEMETER satellite in connection with the 2009 L'Aquila earthquake. Ann Geophys 36(5): 1483-1493.

Balan N, Shiokawa K, Otsuka Y, Kikuchi T, Vijaya Lekshmi D, Kawamura S, Yamamoto M, Bailey G. 2010. A physical mechanism of positive ionospheric storms at low latitudes and midlatitudes. J Geophys Res 115(A2): A02304. DOI: 10.1029/2009JA014515.

Balan N, Liu L, Le H. 2018. A brief review of equatorial ionization anomaly and ionospheric irregularities. Earth Planet Phys 2(4): 257-275.

Chen PR. 1992. Two-day oscillation of the equatorial ionization anomaly. J Geophys Res: Space Phys 97(A5): 6343-6357.

Cherniak I, Krankowski A, Zakharenkova I. 2014. Observation of the ionospheric irregularities over the Northern Hemisphere: Methodology and service. Radio Sci 49(8): 653-662.

Cesaroni C, Spogli L, Alfonsi L, De Franceschi G, Ciraolo L, Monico JFG, Scotto C, Romano V, Aquino M, Bougard B. 2015. L-band scintillations and calibrated total electron content gradients over Brazil during the last solar maximum. J Space Weather Space Clim 5: A36.

Cicone A, Liu J, Zhou H. 2016a. Hyperspectral chemical plume detection algorithms based on multidimensional iterative filtering decomposition. Phil Trans R Soc A: Math Phys Eng Sci 374 (2065): 2015.0196. DOI: 10.1098/rsta.2015.0196.

Cicone A, Liu J, Zhou H. 2016b. Adaptive local iterative filtering for signal decomposition and instantaneous frequency analysis. Appl Comput Harmon Anal 41(2): 384-411. DOI: 10.1016/j.acha. 2016.03.001.

Cicone A, Zhou H. 2017. Multidimensional iterative filtering method for the decomposition of high-dimensional non-stationary signals. Numer Math Theory Methods Appl 10(2): 278-298. DOI: 10.4208/ nmtma.2017.s05.

Cicone A, Zhou H. 2018. Numerical analysis for iterative filtering with new efficient implementations based on FFT. Preprint arXiv:1802.01359.

Cicone A, Dell'Acqua P. 2019. Study of boundary conditions in the iterative filtering method for the decomposition of nonstationary signals. J Comput Appl Math. DOI: 10.1016/j.cam.2019.04.028. Preprint arXiv:1811.07610.

Cicone A. 2019. Nonstationary signal decomposition for dummies. In: Advances in mathematical methods and high performance computing. Advances in mechanics and mathematics, vol. 41, Singh V, Gao D, Fischer A (Eds.), Springer Nature, Cham, Switzerland. DOI: 10.1007/978-3-030-02487-1_3. Preprint arXiv:1710.04844.

Cohen L. 2001. The uncertainty principle for the short-time Fourier transform and wavelet transform. In: Wavelet transforms and timefrequency signal analysis. Applied and numerical harmonic analysis, Debnath L, (Ed.), Birkhäuser, Boston, MA. DOI: 10.1007/978-1-4612-0137-3_8.

Consolini G, Kretzschmar M, Lui AT, Zimbardo G, Macek WM. 2005. On the magnetic field fluctuations during magnetospheric tail current disruption: A statistical approach. J Geophys Res Space Phys 110(A7): A07202.

Davis TN, Sugiura M. 1966. Auroral electrojet activity index AE and its universal time variations. J Geophys Res 71(3): 785-801.

de Oliveira Moraes A, Muella MT, de Paula ER, de Oliveira CB, Terra WP, Perrella WJ, Meibach-Rosa PR. 2018. Statistical evaluation of GLONASS amplitude scintillation over low latitudes in the Brazilian territory. Adv Space Res 61(7): 1776-1789.

Fejer BG. 2011. Low latitude ionospheric electrodynamics. Space Sci Rev 158(1): 145-166.

Fejer BG, Blanc M, Richmond AD. 2017. Post-storm middle and low-latitude ionospheric electric fields effects. Space Sci Rev 206(1-4): 407-429.

Flandrin P. 1998. Time-frequency/time-scale analysis, vol. 10, Academic Press, Inc., Orlando, FL, USA. C 1998. ISBN:0122598709 9780122598708.

Huang NE, Shen Z, Long SR, Wu MC, Shih HH, Zheng Q, Yen NC, Tung CC, Liu HH. 1998. The empirical mode decomposition and the Hilbert spectrum for nonlinear and nonstationary time series analysis. Proc R Soc Lond A 454: 903-995.

Jin SG, Luo O, Park P. 2008. GPS observations of the ionospheric F2-layer behavior during the 20th November 2003 geomagnetic storm over South Korea. J Geodesy 82(12): 883-892. DOI: 10.1007/s00190-008-0217-x.

Kelley MC. 2009. The Earth's ionosphere: Plasma physics and electrodynamics, 2nd edition, Academic Press (Elsevier), San Diego, CA USA.

Koskinen HE, Tanskanen EI. 2002. Magnetospheric energy budget and the epsilon parameter. J Geophys Res Space Phys 107(A11): SMP 42-1-SMP 42-10. 
Kintner PM, Humphreys T, Hinks J. 2009. GNSS and ionospheric scintillation - How to survive to the next solar maximum, InsideGNSS, July/August 2009, 22-30.

Lyatskaya S, Lyatsky W, Khazanov GV. 2009. Auroral electrojet AL index and polar magnetic disturbances in two hemispheres. J Geophys Res Space Phys 114(A6): A06212. DOI: 10.1029/2009JA014100.

Mannucci AJ, Wilson BD, Edwards CD. 1993. A new method for monitoring the Earth ionosphere total electron content using the GPS global network. Proc ION GPS-93: 1323-1332.

Mannucci A, Tsurutani B, Iijima B, Komjathy A, Saito A, Gonzalez W, Guarnieri F, Kozyra J, Skoug R. 2005. Dayside global ionospheric response to the major interplanetary events of October 29-30, 2003 "Halloween storms". Geophys Res Lett 32 (12): L12S02. DOI: 10.1029/2004GL021467.

Materassi M, Alfonsi L, De Franceschi G, Mitchell CN, Romano V, Spalla P, Wernik AW, Yordanova E. 2005. Intermittency and ionospheric scintillations in GPS data. In: Proceedings of the International Workshop on Applications of Wavelets to Real World Problems (IWW2005), vol. 17, p. 18.

Materassi M, Mitchell CN. 2007. Wavelet analysis of GPS amplitude scintillation: A case study. Radio Sci 42(1): RS1004. DOI: $10.1029 / 2005 R S 003415$.

McComas DJ, Bame SJ, Barker P, Feldman WC, Phillips JL, Riley P, Griffee JW. 1998. Solar Wind Electron Proton Alpha Monitor (SWEPAM) for the advanced composition explorer. Space Sci Rev 86(1): 563-612.

Muella MTAH, Kherani EA, de Paula ER, Cerruti AP, Kintner PM, Kantor IJ, Mitchell CN, Batista IS, Abdu MA. 2010. Scintillationproducing Fresnel-scale irregularities associated with the regions of steepest TEC gradients adjacent to the equatorial ionization anomaly. J Geophys Res 115: A03301. DOI: 10.1029/2009JA014788.

Nishida A. 1968. Coherence of geomagnetic DP 2 fluctuations with interplanetary magnetic variations. $J$ Geophys Res 73(17): 5549-5559.

Olwendo OJ, Cesaroni C, Yamazaki Y, Cilliers P. 2017. Equatorial ionospheric disturbances over the East African sector during the 2015 St. Patrick's day storm. Adv Space Res 60(8): 1817-1826.

Perreault P, Akasofu S-I. 1978. A study of geomagnetic storms. Geophys J R Astron Soc 54: 547-573.

Piersanti M, Alberti T, Bemporad A, Berrilli F, Bruno R, et al. 2017. Comprehensive analysis of the geoeffective solar event of 21 June 2015: Effects on the magnetosphere, plasmasphere, and ionosphere systems. Solar Phys 292: 169. DOI: 10.1007/s11207-017-1186-0.

Piersanti M, Materassi M, Cicone A, Spogli L, Zhou H, Ezquer RG. 2018. Adaptive local iterative for the analysis of nonstationary signals. J Geophys Res Space Phys 123: 1031-1046. DOI: 10.1002/2017JA024153.

Rastogi RG. 1989. The equatorial electrojet: Magnetic and ionospheric effects. In: Geomagnetism, Jacobs J, (Ed.), Academic, New York, NY, vol. 3, pp. 461-525.

Rishbeth H. 1971. Polarization fields produced by winds in the equatorial F region. Planet Space Sci 19: 357-369. DOI: 10.1016/ 0032-0633(71)90098-5.

Sanz J, Juan J, González-Casado G, Prieto-Cerdeira R, Schlueter S, Orus R. 2014. Novel ionospheric activity indicator specifically tailored for GNSS users. In: Proceedings of ION GNSS+ 2014, Tampa, Florida (USA), pp. 1173-1182. http://www.ion.org/ publications/abstract.cfm?.jp=p\&articleID $=12269$.
Scherliess L, Fejer BG. 1997. Storm time dependence of equatorial disturbance dynamo zonal electric fields. J Geophys Res Space Phys 102(A11): 24037-24046.

Smith CW, L'Heureux J, Ness NF, Acuña MH, Burlaga LF, Scheifele J. 1998. The ACE magnetic fields experiment. Space Sci Rev 86(1): 613-632.

Spogli L, Alfonsi L, De Franceschi G, Romano V, Aquino MHO, Dodson A. 2009. Climatology of GPS ionospheric scintillations over high and mid-latitude European regions. Ann. Geophys 27: 3429-3437.

Spogli L, Alfonsi L, Romano V, De Franceschi G, Francisco GMJ, Shimabukuro MH, Bougard B, Aquino M. 2013. Assessing the GNSS scintillation climate over Brazil under increasing solar activity. J Atmos Solar-Terr Phys 105: 199-206. DOI: 10.1016/ j.jastp.2013.10.003.

Spogli L, Cesaroni C, Di Mauro D, Pezzopane M, Alfonsi L, et al. 2016. Formation of ionospheric irregularities over Southeast Asia during the 2015 St. Patrick's Day storm. J Geophys Res Space Phys 121(12): 1-12.

Tsurutani B, Mannucci A, Iijima B, Abdu MA, Sobral JHA, et al. 2004. Global dayside ionospheric uplift and enhancement associated with interplanetary electric fields. J Geophys Res 109(A8).

Tsurutani B, Verkhoglyadova O, Mannucci A, Saito A, Araki T, et al. 2008. Prompt penetration electric fields (ppefs) and their ionospheric effects during the great magnetic storm of 30-31 October 2003. J Geophys Res 113(A5).

Tulasi Ram S, Yokoyama T, Otsuka Y, Shiokawa K, Sripathi S, et al. 2016. Duskside enhancement of equatorial zonal electric field response to convection electric fields during the St. Patrick's Day storm on 17 March 2015. J Geophys Res Space Phys 121: 538-548. DOI: $10.1002 / 2015 J A 021932$.

Van Dierendonck AJ, Klobuchar J, Hua Q. 1993. Ionospheric scintillation monitoring using commercial single frequency C/A code receivers. In: Paper presented at the Sixth International Technical Meeting (ION GPS-93), Satell. Div., Inst. of Navig., Salt Lake City, Utah, 22-24 Sept.

Venkatesh K, Tulasi Ram S, Fagundes P, Seemala GK, Batista I. 2017. Electrodynamic disturbances in the Brazilian equatorial and low-latitude ionosphere on St. Patrick's Day storm of 17 March 2015. J Geophys Res 122(4): 4553.

Wei Y, Zhao B, Li G, Wan W. 2015. Electric field penetration into Earth's ionosphere: A brief review for 2000-2013. Sci Bull 60(8): 748-761.

Wernik AW, Liu CH. 1974. Ionospheric irregularities causing scintillations of $\mathrm{GHz}$ frequency radio signals. J Atmos Terr Phys 36: 871-879. DOI: 10.1016/0021-9169(74)90032-4.

Wernik AW. 1997. Wavelet transform of nonstationary ionospheric scintillation. Acta Geophys Pol XLV: 237-253.

Wernik AW, Secan JA, Fremouw EJ. 2003. Ionospheric irregularities and scintillation. Adv Space Res 31(4): 971-981. DOI: 10.1016/ S0273-1177(02)00795-0.

Yeh KC, Liu CH. 1982. Radio wave scintillations in the ionosphere. Proc IEEE 70(4): 324-360.

Zong Q-G, Reinisch B, Song P, Wei Y, Galkin I. 2010. Dayside ionospheric response to the intense interplanetary shocks-solar wind discontinuities: Observations from the digisonde global ionospheric radio observatory. J Geophys Res 115(A6): A06304. DOI: $10.1029 / 2009 J A 014796$.

Cite this article as: Spogli L, Piersanti M, Cesaroni C, Materassi M, Cicone A, et al. 2019. Role of the external drivers in the occurrence of low-latitude ionospheric scintillation revealed by multi-scale analysis. J. Space Weather Space Clim. 9, A35. 